Вип. 1, 2019

УДК 621.313.3

М. А. Яцун

Національний університет “Львівська політехніка", кафедра електромехатроніки та комп’ютеризованих електромеханічних систем, Yacunma@gmail.com

\title{
ВИХІДНА НАПРУГА ЛОКАЛЬНОГО ПЕРВИННОГО ВНУТРІШНЬОГО ВИХРОСТРУМОВОГО ПЕРЕТВОРЮВАЧА ТРАНСФОРМАТОРНОГО ТИПУ В ЕЛЕКТРОПРОВІДНІЙ ФЕРОМАГНІТНІЙ ТРУБІ
}

https://doi.org/10.23939/sepes2019.01.085

(C) Яиун М. А., 2019

Під час діагностування технічного стану магістральних трубопроводів (газопроводів) виявляють дефекти типу порушення суцільності, встановлюють фактичну товщину стінки трубопроводу і визначають профіль його поверхні. На основі акустичного (ультразвукового), магнітного і вихрострумового методів контролю розроблено інтелектуальні поршні, які використовують для внутрішньотрубної технічної діагностики. Вихрострумовий метод контролю дас можливість виявити поверхневі тріщини із малим розкриттям та дефекти розшарування металу трубопроводу. За вихрострумового методу контролю первинний прохідний перетворювач параметричного або трансформаторного типу зазвичай мас форму циліндричної котушки із прямокутною формою поперечного перерізу i розташований співвісно з контрольованою трубою.

3 метою контролю дефектів, товщини стінки і фізичних параметрів електропровідних феромагнітних труб для локалізації магнітного поля обмотку збудження первинного перетворювача доцільно виконати у формі двох кільцевих котушок, співвісних із контрольованою трубою, у яких протікатимуть протилежно спрямовані струми. Тоді для локального контролю вимірну (вторинну) обмотку первинного перетворювача доцільно розташувати біля внутрішньої поверхні труби між котушками обмотки збудження так, щоб їі вісь була спрямована по радіусу труби і такий первинний перетворювач обертати по колу й переміщувати в осьовому напрямі або передбачити декілька таких вимірних обмоток по колу труби і переміщувати перетворювач тільки по осі труби. Тому актуальним с розрахунок вихідної інформації (напруги на вимірній обмотці) прохідного екранованого вихрострумового первинного перетворювача трансформаторного типу, розташованого всередині контрольованої.

Визначені основна, внесена об'єктом контролю, і сумарна перетворені за Лапласом напруги на вимірній обмотці первинного внутрішнього вихрострумового перетворювача прохідного типу із обмоткою збудження, яка складасться із двох зустрічно увімкнених кільцевих циліндричних котушок прямокутного поперечного перерізу зі струмом заданої форми, і вимірної обмотки, розташованої біля внутрішньої поверхні труби між котушками обмотки збудження так, щоб її вісь була спрямована по радіусу труби.

Отримані результати доцільно використати під час діагностування технічного стану внутрішньої поверхні трубопроводів для визначення інформативних величин та їх 
чутливостей до параметрів і дефектів об'єкта контролю розглянутим прохідним первинним вихрострумовим перетворювачем з метою розв'язки багатопараметрової інформації.

Ключові слова: вихідна напруга; внутрішній прохідний вихрострумовий перетворювач; обмотка збудження; вимірна обмотка; діагностування трубопроводів.

\section{Постановка проблеми}

Під час діагностування технічного стану магістральних трубопроводів (газопроводів) виявляють дефекти типу порушення суцільності, встановлюють фактичну товщину стінки трубопроводу і визначають профіль його поверхні. На основі акустичного (ультразвукового), магнітного і вихрострумового методів контролю розроблено інтелектуальні поршні, які використовують під час внутрішньотрубної технічної діагностики [1-6]. Вихрострумовий метод контролю дає можливість виявити поверхневі тріщини 3 малим розкриттям та дефекти розшарування металу трубопроводу. Первинний прохідний перетворювач параметричного або трансформаторного типу для вихрострумового методу контролю зазвичай має форму циліндричної котушки із прямокутною формою поперечного перерізу і розташований співвісно із контрольованою трубою. Обмотку збудження первинного перетворювача для контролю дефектів, товщини стінки і фізичних параметрів електропровідних феромагнітних труб для локалізації магнітного поля доцільно виконати у формі двох кільцевих котушок, співвісних із контрольованою трубою, у яких протікатимуть протилежно спрямовані струми. Тоді для локального контролю вимірну (вторинну) обмотку первинного перетворювача доцільно розташувати біля внутрішньої поверхні труби між котушками обмотки збудження так, щоб їі вісь була спрямована по радіусу труби, обертати по колу такий первинний перетворювач і переміщувати в осьовому напрямі або передбачити декілька таких вимірних обмоток по колу труби і переміщувати перетворювач тільки по осі труби. Тому актуальним $є$ розрахунок вихідної інформації прохідного екранованого вихрострумового первинного перетворювача трансформаторного типу, розташованого всередині контрольованої труби. Розрахункову модель такого перетворювача подано на рисунку.

\section{Аналіз останніх досліджень}

Магнітне поле збуджуючої котушки реєструється сенсорними котушками на відстані двох та більше діаметрів труби. Електромагнітні коливання, які проникають у стінку трубопроводу, залежать від будь-яких дефектів біля сенсорної котушки. Точність відомого методу $[4,5]$ на рівні методу вимірювання магнітного потоку. До недоліків цього методу належить значне енергоспоживання та невелика швидкодія. Подальші дослідження викладено у [7-11]. У [8] визначено перетворений за Лапласом векторний потенціал магнітного поля, радіальну й осьову складові магнітної індукції первинного внутрішнього вихрострумового перетворювача прохідного типу із обмоткою збудження, яка складається із двох зустрічно увімкнених екранованих кільцевих циліндричних котушок прямокутного поперечного перерізу зі струмом довільної форми, які охоплюють вимірну обмотку, всі обмотки розташовані всередині співвісно із віссю труби.

\section{Виклад основного матеріалу}

На рисунку прийнято такі позначення: $a_{1}$ i $b_{1}$ - розміри (ширина і висота) поперечного перерізу кожної із обмоток збудження (1); $a_{2}$ i $b_{2}$ - розміри (ширина і висота) поперечного перерізу вимірної обмотки (2) у формі квадратної (прямокутної) дугової рамки прямокутного поперечного перерізу; $c_{3}$ і $c_{4}$ - внутрішній і зовнішній розміри вимірної обмотки; $\left|h_{1}\right|$ i $\left|h_{2}\right|$ - ординати обмоток збудження; $h_{3}$ - відстань внутрішньої поверхні вимірної обмотки від осі труби; $r_{5}, r_{6}$ і $d-$ внутрішній і зовнішній радіуси і товщина контрольованої труби; $\mu$ і $\gamma$ - абсолютна магнітна проникність і питома електрична провідність труби; $R$ і $H$ - радіус і висота екрана (досліджуваного простору), який охоплює об'єкт контролю (щоб спростити розв'язання, екран вибираємо надпровідним); 1 , 2 і 3 - області всередині екрана. Вважаємо, що області всередині і зовні труби (1 i 3) неферомагнітні ( $\mu=\mu_{0}$, де $\mu_{0}$ - магнітна стала) і мають питому електричну провідність $\gamma=0$. Напрями струму і густини струму в обмотках збудження протилежні. 
Вихідна напруга локального первинного внутрішнього вихрострумового перетворювача...

Розрахункова модель первинного вихрострумового екранованого перетворювача трансформаторного типу всередині контрольованої труби

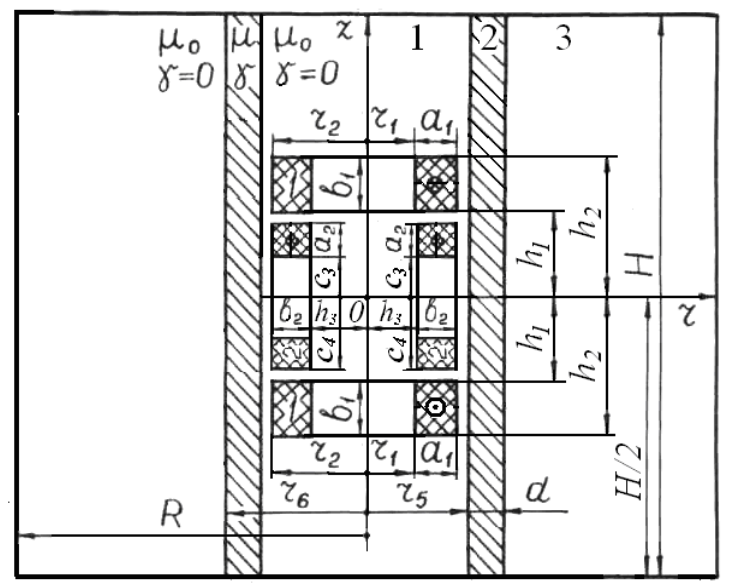

Із [8] для векторного потенціалу магнітного поля в області 1 (всередині труби) маємо:

$$
\tilde{A}_{1}=\tilde{A}_{0}+\tilde{A}_{16}=\mu_{0} \tilde{\delta}_{01} \sum_{i=1}^{\infty} \sum_{k=1}^{\infty} \frac{a_{i 1} b_{k 01}}{n_{i}^{2}+m_{k}^{2}} J_{1}\left(n_{i} r\right) \sin m_{k} z+\tilde{\delta}_{01} \sum_{k=1}^{\infty} C_{11} I_{1}\left(p_{1} r\right) \sin m_{k} z,
$$

де перша складова виражає векторний потенціал за відсутності об'єкта контролю, а друга - внесена об'єктом контролю.

Тоді для радіальної складової (по осі $r$ ) магнітної індукції отримаємо:

для основної (за відсутності об’єкта контролю)

$$
\tilde{B}_{r 0}=-\frac{\partial \tilde{A}_{0}}{\partial z}=-\mu_{0} \tilde{\delta}_{01} \sum_{i=1}^{\infty} \sum_{k=1}^{\infty} \frac{m_{k} a_{i 1} b_{k 01}}{n_{i}^{2}+m_{k}^{2}} J_{1}\left(n_{i} r\right) \cos m_{k} z ;
$$

для внесеної об'єктом контролю

$$
\tilde{B}_{r 1 b}=-\frac{\partial \tilde{A}_{1 b}}{\partial z}=-\tilde{\delta}_{01} \sum_{k=1}^{\infty} m_{k} C_{11} I_{1}\left(p_{1} r\right) \cos m_{k} z
$$

і сумарної

$$
\tilde{B}_{r 1}=-\frac{\partial \tilde{A}_{1}}{\partial z}=-\mu_{0} \tilde{\delta}_{01} \sum_{i=1}^{\infty} \sum_{k=1}^{\infty} \frac{m_{k} a_{i 1} b_{k 01}}{n_{i}^{2}+m_{k}^{2}} J_{1}\left(n_{i} r\right) \cos m_{k} z-\tilde{\delta}_{01} \sum_{k=1}^{\infty} m_{k} C_{11} I_{1}\left(p_{1} r\right) \cos m_{k} z,
$$

де

$$
\tilde{\delta}_{0}=\tilde{\delta}_{01} \sum_{i=1}^{\infty} \sum_{k=1}^{\infty} a_{i 1} b_{k 01} J_{1}\left(n_{i} r\right) \sin \left(m_{k} z\right) \text {, - густина струму в обмотці збудження, розкладена у }
$$

подвійний ряд: ряд Фур'є-Бесселя по координаті $r$ і синусний ряд Фур'є по координаті $z ; \widetilde{\delta}_{01}-$ зображення за Лапласом густини струму в котушках обмотки збудження давача, якщо $\mathrm{r}_{1} \leq \mathrm{r} \leq \mathrm{r}_{2} \mathrm{i}$ $\mathrm{h}_{1} \leq|\mathrm{z}| \leq \mathrm{h}_{2}$, а в іншій частині першої області $\vec{\delta}_{0}=0 ; m_{k}=2 k \pi / H ; n_{i}=\lambda_{i} / R ; \lambda_{1}, \lambda_{2}, \ldots, \lambda_{i}, \ldots-$ корені рівняння $\mathrm{J}_{1}(\lambda)=0 ; \mathrm{a}_{\mathrm{i} 1}-$ коефіцієнт ряду Фур'є-Бесселя функції $f_{1}(r)=1$, якщо $r_{1} \leq r \leq r_{2}$ i $f_{1}(r)=0$, якщо $0 \leq r \leq r_{1}$ i $r_{2} \leq r \leq R$, розкладеної у проміжку $(0, \mathrm{R}) ; a_{i 1}=\int_{0}^{R} f_{1}(r) J_{1}\left(n_{i} r\right) r d r / J_{1}^{2}=\frac{2 Y_{1}}{R^{2} J_{0}^{2}\left(\lambda_{i}\right)}, J_{0} \mathrm{i}$ $J_{1}$ - функція Бесселя першого роду нульового і першого порядків;

$$
\begin{aligned}
& Y_{1}=\int_{0}^{R} f_{1}(r) J_{1}\left(n_{i} r\right) r d r=\int_{r_{1}}^{r_{2}} f_{1}(r) J_{1}\left(n_{i} r\right) r d r=\int_{r_{1}}^{r_{2}} J_{1}\left(n_{i} r\right) r d r= \\
& \frac{1}{n_{i}}\left\{r_{1} J_{0}\left(n_{i} r_{1}\right)-r_{2} J_{0}\left(n_{i} r_{2}\right)+\frac{2}{n_{i}}\left[J_{1}\left(n_{i} r_{2}\right)-J_{1}\left(n_{i} r_{1}\right)+J_{3}\left(n_{i} r_{2}\right)-J_{3}\left(n_{i} r_{1}\right)+J_{5}\left(n_{i} r_{2}\right)-J_{5}\left(n_{i} r_{1}\right)+\ldots\right]\right\}-
\end{aligned}
$$

ряд, який швидко збігається; 
$b_{k 01}=\frac{4}{H} \int_{h_{1}}^{h_{2}} \sin m_{k} z d z=\frac{8}{m_{k} H} \sin m_{k} \frac{b_{1}}{2} \sin m_{k}\left(\frac{h_{1}+h_{2}}{2}\right)-$ коефіцієнт ряду Фур'є розкладеної у проміжку $-H / 2 \leq z \leq H / 2$ функції $\mathrm{f}_{2}(z)=1$, якщо $h_{1} \leq z \leq h_{2}$ i $\mathrm{f}_{2}(z)=-1$, якщо $-h_{2} \leq z \leq-h_{1}$, а в інших частинах області 1 (рис. 1) $\mathrm{f}_{2}(z)=0$;

$$
\begin{aligned}
& J_{1}^{2}=\frac{R^{2}}{2}\left[J_{1}\left(\lambda_{i}\right)\right]^{2}=\frac{R^{2}}{2} J_{0}^{2}\left(\lambda_{i}\right)-\text { квадрат норми; } \\
& C_{11}=\frac{\mu N_{1} P_{1} I_{1}\left(p_{2} r_{5}\right)+\mu N_{2} P_{1} K_{1}\left(p_{2} r_{5}\right)-P_{2} D_{1}}{P_{2} I_{1}\left(p_{1} r_{5}\right)} \\
& N_{1}=\mu_{0} p_{2} M_{1} K_{0}\left(p_{2} r_{6}\right)+\mu p_{3} M_{2} K_{1}\left(p_{2} r_{6}\right) ; \\
& N_{2}=\mu_{0} p_{2} M_{1} I_{0}\left(p_{2} r_{6}\right)-\mu p_{3} M_{2} I_{1}\left(p_{2} r_{6}\right) ; \\
& P_{1}=D_{2} I_{1}\left(p_{1} r_{5}\right)-p_{1} D_{1} I_{0}\left(p_{1} r_{5}\right) ; \\
& P_{2}=\mu_{0} p_{2} I_{1}\left(p_{1} r_{5}\right)\left[N_{1} I_{0}\left(p_{2} r_{5}\right)-N_{2} K_{0}\left(p_{2} r_{5}\right)\right]-\mu p_{1} I_{0}\left(p_{1} r_{5}\right)\left[N_{1} I_{1}\left(p_{2} r_{5}\right)+N_{2} K_{1}\left(p_{2} r_{5}\right)\right] ;
\end{aligned}
$$

$I_{1}$ і $K_{1}$ - модифіковані циліндричні функції Бесселя першого порядку першого і другого родів; $I_{0}$ і $K_{0}$ - модифіковані циліндричні функції Бесселя нульового порядку першого і другого родів; $p_{1}^{2}=m_{k}^{2}+p \gamma_{1} \mu_{0} ; p_{2}^{2}=m_{k}^{2}+p \gamma \mu$.

Тоді за умови, що в початковий момент часу $\mathrm{u}_{2}(0)=0$, перетворена за Лапласом напруга на вимірній обмотці:

основна (за відсутності об’єкта контролю)

$$
\tilde{U}_{20}=2 w_{2}\left(2 c_{5}+a_{2}\right)\left[\int_{0}^{c_{3}} \tilde{B}_{r 0} d z+\int_{c_{3}}^{c_{4}}\left(z-c_{3}\right) \tilde{B}_{r 0} d z\right]
$$

внесена

$$
\tilde{U}_{2 \beta}=2 w_{2}\left(2 c_{5}+a_{2}\right)\left[\int_{0}^{c_{3}} \tilde{B}_{r 16} d z+\int_{c_{3}}^{c_{4}}\left(z-c_{3}\right) \tilde{B}_{r 16} d z\right]
$$

і сумарна

$$
\tilde{U}_{2}=2 w_{2}\left(2 c_{5}+a_{2}\right)\left[\int_{0}^{c_{3}} \tilde{B}_{r 1} d z+\int_{c_{3}}^{c_{4}}\left(z-c_{3}\right) \tilde{B}_{r 1} d z\right]
$$

де $c_{5}$ - внутрішній розмір вимірної обмотки по дуговій координаті у випадку прямокутного контуру обмотки збудження , а у випадку квадратного контуру обмотки збудження $c_{5}=c_{3}$.

Якщо $H \rightarrow \infty$ i $|z| \leq h_{1}$ :

$$
\begin{gathered}
\tilde{A}_{0}=2 \mu_{0} \tilde{\delta}_{01} \sum_{i=1}^{\infty} a_{i 1} J_{1}\left(n_{i} r\right) \frac{\operatorname{sh}\left(n_{i} z\right)}{n_{i}^{2}} \operatorname{sh} n_{i}\left(b_{1} / 2\right) e^{-n_{i}\left(h_{1}+h_{2}\right) / 2} \\
B_{r 0}=-\frac{\partial A_{0}}{\partial z}=-2 \mu_{0} \tilde{\delta}_{01} \sum_{i=1}^{\infty} a_{i 1} J_{1}\left(n_{i} r\right) \frac{\operatorname{ch}\left(n_{i} z\right)}{n_{i}} \operatorname{sh} n_{i}\left(b_{1} / 2\right) e^{-n_{i}\left(h_{1}+h_{2}\right) / 2} .
\end{gathered}
$$

Перехід від функції-зображення $U_{2}(p)$ до функції-оригіналу $u_{2}(t)$ (миттєвого значення напруги у вимірній обмотці) можна виконати за методом, розробленим у $[10,11]$, якщо задано зображення густини струму $\widetilde{\delta}_{01}$ в обмотці збудження. 
Вихідна напруга локального первинного внутрішнього вихрострумового перетворювача...

\section{Висновки}

Отримані вирази для основної, внесеної об’єктом контролю і сумарної перетвореної за Лапласом напруги на вимірній обмотці первинного внутрішнього вихрострумового перетворювача прохідного типу з обмоткою збудження, яка складається із двох зустрічно увімкнених кільцевих циліндричних котушок прямокутного поперечного перерізу зі струмом заданої форми, і вимірної обмотки, розташованої біля внутрішньої поверхні труби між котушками обмотки збудження так, щоб іiі вісь була спрямована по радіусу труби. Таке виконання обмотки збудження і вимірної обмотки первинного вихрострумового перетворювача трансформаторного типу, розташованого всередині контрольованої труби, доцільно використовувати для локалізації та кращої однорідності магнітного поля під час діагностування технічного стану внутрішньої поверхні трубопроводів.

\section{Список використаних джерел}

1. Muzhitsky V. F. Computerized Eddy Current Flaw Detector VD-89 NM with Higher Reliability of Detection and Danger Level estimation of Stress-corrosion cracks when Inspecting Gas Pipeline under StressCorrosion / V. F. Muzhitsky, V. A. Karabtchewski // Pipeline 트 Gas Journal, 2002, vol. 2, pp. 35-44.

2. Pipeline Inspection Technologies Demonstration Report / Gas Research Institute, 2004. 98 p.

3. Albert Teisma. Technical Assessment Report Technology Assessment for Delivery Reliability for Natural Gas / Gas Technology Institute, 2004. 56 p.

4. Remote Field Eddy Current Defect Interaction, GRI Final Report GRI-95/0506. December 1995. Atherton, D. L., Clapham, L., Czura, W., Mergelas, B. J., Smith, S., Winslow, J., Zhang, Y. / Gas Research Institute, $1995.125 \mathrm{p}$.

5. Experience with the Remote Field Eddy Current Technique / Schmidt T. R., Atherton D. L., Sullivan S. // Proc. of $3 r d$ Nat. Sem. on Nondestructive Evaluation of Ferromagnetic Materials, Houston, March 23-25th, 1988, pp. 89-97.

6. Delivery Reliability for Natural Gas - Inspection Technologies. Technical Semiannual Progress Report DE-FC26-04NT42266 / Gas Technology Institute, 2005. 215 p.

7. Яиун М. А., Яиун А. М. Векторний потенціал магнітного поля прохідного кільцевого вихрострумового первинного перетворювача параметричного і трансформаторного типів у провідній трубі // Вісник Національного університету “Львівська політехніка" “Електроенергетичні та електромеханічні системи”, № 763. - Львів: Вид. Львівської політехніки, 2013. - С. 120-126.

8. Яиун М. А., Яиун А. М. Векторний потенціал і складові магнітної індукції магнітного поля прохідного вихрострумового перетворювача у провідній трубі // Відбір і обробка інформації, 2016. Bun. 43 (119). C. 12-20.

9. Яиун М. А. Складові магнітної індукиії обмотки збудження прохідного вихрострумового перетворювача у провідній трубі. Вісник Наиіонального університету "Львівська політехніка" "Електроенергетичні та електромеханічні системи", № 900. Львів: Вид-во Львівської політехніки, 2018. С. 67-71.

10. Яиун М. А., Яиун А.М. Наближене чисельне обернення перетворення Лапласа аперіодичних перехідних величин при неруйнівному контролі імпульсним вихрострумовим методом // Вісн. Національного університету “Львівська політехніка". 2009. № 654 . С. 285-290.

11. Яиун М. А., Яиун А. М., Шуплат О. І. Наближена числова реалізація зворотного перетворення Лапласа загасаючих коливань у разі неруйнівного контролю імпульсним вихрострумовим методом // Вісн. Національного університету “Львівська політехніка”, 2010. № 671. С. 140-146.

\section{References}

1. Muzhitsky V. F. Computerized Eddy Current Flaw Detector VD-89NM with Higher Reliability of Detection and Danger Level esstimation of Stress-corrosion cracks when Inspecting Gas Pipeline under Stress-Corrosion /V. F. Muzhitsky, V. A. Karabtchewski // Pipeline $\underline{\&}$ Gas Journal. 2002. Vol. 2. P. 35-44.

2. Pipeline Inspection Technologies Demonstration Report. Gas Research Institute. 2004. 98 p.

3. Albert Teisma. Technical Assessment Report Technology Assessment for Delivery Reliability for Natural Gas. Gas Technology Institute. 2004. 56 p. 
4. Remote Field Eddy Current Defect Interaction, GRI Final Report GRI-95/0506. December 1995. Atherton, D. L., Clapham, L., Czura, W., Mergelas, B. J., Smith, S., Winslow, J., Zhang, Y. Gas Research Institute. 1995. 125p.

5. Experience with the Remote Field Eddy Current Technique / Schmidt T. R., Atherton D. L., Sullivan S. // Proc. of 3rd Nat. Sem. on Nondestructive Evaluation of Ferromagnetic Materials, Houston, March 23-25th, 1988. 1988. P. 89-97.

6. Delivery Reliability for Natural Gas - Inspection Technologies. Technical Semiannual Progress Report DEFC26-04NT42266. Gas Technology Institute. 2005. 215 .

7. Jacun M. A., Jacun A. M. Wektornyj potencial magnitnoho polja prochidnogo kilcewogo wychrostrumowogo perwynnogo peretworjuwaca parametrycnogo $i$ transformatornogo typiw u prowidnij trubi. Wisnyk NU "LP" "Elektroenergetycni ta electromechanicni systemy", No. 763. Lwiw: Wyd. Lwiwskoji politechniky, 2013, s. 120-126.

8. Jacun M. A., Jacun A. M. Wektornyj potencial i skladowi magnitnoji indukciji magnitnoho polja prochidnogo wychrostrumowogo peretworjuwaca u prowidnij trubi // Widbir $i$ obrobka informaciji, 2016 r. Wyp. 43 (119), s. 12-20.

9. Jacun M.A. Skladowi magnitnoji indukciji obmotky zbudgennja prochidnogo wychrostrumowogo peretworjuwaca u prowidnij trubi. Wisnyk NU “LP”" “Elektroenergetycni ta electromechanicni systemy”, №900.Lwiw: Wyd. Lwiwskoji politechniky, 2018 r., s. 67-71.

10. Jacun M. A., Jacun A.M. Nablygene cyselne obernennja peretworennja Laplasa aperiodycnysh pereshidnysh welychyn pry nerujniwnomu kontroli impulsnym wyshrostrumowym metodom // Wisn. NU "Lwiwska politechnika”. 2009. No. 654. S. 285-290.

11. Jacun M. A., Jacun A. M., Shuplat O. I. Nablygena chyslowa realizacija zworotnogo peretworennja Laplasa zagasajuchysh kolywan u razi nerujniwnogo kontrolu impulsnym wyshrostrumowym metodom // Wisn. NU "Lwiwska politechnika”. 2010. No. 671. S. 140-146.

M. A. Yatsun

Lviv Polytechnic National University, Department of Electromechatronics and Computerized Electromechanical Systems, Yacunma@gmail.com

\section{INITIAL TENSION OF LOCAL PRIMARY INTERNAL EDDY CURRENT TRANSFORMER OF TRANSFORMER TYPE IS IN A ELECTRIC CONDUCTION FERROMAGNETIC PIPE}

(C) Yatsun M. A., 2019

At diagnosticating of the technical state of main pipelines (gas pipelines) violations of wholenes find out defects as, set the actual thickness of wall of pipeline, and determine to the profile of his surface. On the basis of acoustic (ultrasonic), magnetic and eddy current methods of control intellectual pistons that is used for inwardly pipe technical diagnostics are worked out. Eddy current a control method gives an opportunity to educe superficial cracks with the small opening and defects of stratification of metal of pipeline. At the eddy current method of control the primary communicating transformer of selfreactance or transformer type usually has a form of cylindrical spool with the rectangular form of transversal cut and align is located with the controlled pipe.

At control of defects, thickness of wall and physical parameters of electric conduction ferromagnetic pipes for localization of magnetic field the puttee of excitation of primary transformer it is expedient to execute in form two circular spools, align with the controlled pipe at flowing of the oppositely directed currents in them. Then for local control the measurable (secondary) puttee of primary transformer it is expedient to dispose near the internal surface of pipe between the spools of puttee of excitation so that her axis was directed on the radius of pipe to revolve such primary transformer on a circle and transfer to axial direction, or to provide for a few such measurable windings on the circle of pipe and to move a transformer only for the axes of pipe. Therefore actual is a task of 
calculation of initial information (tension on a measurable puttee) of communicating screened eddy current of primary transformer of the transformer type located into controlled.

Certain basic, brought in object of control and total regenerate after Laplace tension on the measurable puttee of primary internal eddy current transformer of re-entrant with the puttee of excitation, that consists of two meeting included circular cylindrical spools of rectangular transversal cut with the current of true-to-shape, and measurement winding, pipe located near an internal surface between the spools of puttee of excitation so that her axis was directed on the radius of pipe.

The got results it is expedient to draw on at diagnosticating of the technical state of internal surface of pipelines for determination of informing sizes and them sensitivitis to the parameters and defects of object of control to the considered clock-houses by a primary eddy current transformer with the aim of upshot of multi-parameters information.

Key words: initial tension; internal communicating eddy current transformer; puttee of excitation; measurable puttee; diagnosticating. 